\title{
Phosphorylation of RNA Polymerase II in Cardiac Hypertrophy: Cell Enlargement Signals Converge on Cyclin T/Cdk9
}

\author{
Prathit A. Kulkarni,* Motoaki Sano,* and Michael D. Schneider** \\ *Center for Cardiovascular Development and Department of Medicine; ${ }^{\dagger}$ Departments of \\ Molecular and Cellular Biology, and Molecular Physiology and Biophysics, Baylor College of \\ Medicine, Houston, Texas 77030
}

\begin{abstract}
Cardiac myocyte enlargement is the eponymous characteristic of cardiac hypertrophy, regardless of the instigating signal. Such triggers include biomechanical stress (e.g., work load, compensation for ischemic damage), sarcomeric protein mutations, cytoskeletal protein mutations, abnormal energetics, G protein-coupled receptors for ligands (including angiotensin II and endothelin-1), or their signal transducers within cells. In turn, increased myocyte size reflects increased RNA and protein content per cell as responses to these stimuli. In eukaryotic cells, the large subunit of RNA polymerase II (RNAPII) becomes extensively phosphorylated in its serine-rich C-terminal domain (CTD) during the transition from transcript initiation to transcript elongation - that is, "escape" of RNAPII from the promoter-proximal region into the open reading frame. Although this process is believed to be crucial to productive synthesis of mRNA and is known to be governed by two atypical cyclin-dependent kinases, Cdk7 and Cdk9, surprisingly little is understood of how regulatory pathways within cells intersect these RNAPII-directed protein kinases. Investigations of the CTD kinase module in cardiac hypertrophy provide a tentative initial map of a molecular circuit controlling cell size through regulated phosphorylation of RNAPII.
\end{abstract}

\section{Overview}

In pathophysiological terms, and in weighing potential nodal control points for therapeutic interventions, cardiac hypertrophy is usefully viewed as a problem in signal transduction coupled to transcriptional control (Sadoshima and Izumo, 1997; Hunter and Chien, 1999; Molkentin and Dorn, 2001; Akazawa and Komuro, 2003; Frey and Olson, 2003; Olson and Schneider, 2003). Hypertrophy is the normal mode of cardiac growth after birth but also the form of growth the heart exhibits when subjected to biomechanical stresses such as pressure overload (MacLellan and Schneider, 2000; Pasumarthi and Field, 2002). Hemodynamic stress upon the heart can be thought of as extrinsic if resistance to ventricular ejection is increased, such as in hypertension, obstructive valvular disease, or congenital narrowing of the aorta. By contrast, intrinsic hemodynamic 
stress occurs because of diminished pump function, with myocardial infarction the most-prevalent example, or with cardiomyopathic mutations. As the result of increased load, a number of physiological and molecular changes ensue within the myocardium, resulting in the aggregate "hypertrophic phenotype." Teleologically, at least some elements of this response may be salutary, at least in the short run. For instance, concentric hypertrophic growth (ventricular wall thickening) likely serves to ameliorate the abnormal increase in wall stress, per a basic physical principle, the law of Laplace. Morever, alterations in specific genes' expression during hypertrophy are likely to encompass some adaptive or cytoprotective components that benefit cardiomyocyte metabolism, contractility, or survival. However, the adverse aspects of this transcriptional program have received increasing attention and can include the induction of overtly proapoptotic genes that are sufficient, through myocyte death, to trigger organ-level dysfunction (Yussman et al., 2002). Coupling wall stress to cardiac hypertrophic growth and, often, to eventual heart failure involves an intricate web of signal transduction cascades and transcriptional regulators, both in cardiomyocytes themselves and autocrine/paracrine interactions with cardiac fibroblasts and other types of heart cells (Sadoshima and Izumo, 1997; Molkentin and Dorn, 2001; Akazawa and Komuro, 2003; Frey and Olson, 2003; Olson and Schneider, 2003).

How does the heart "know" that it should work harder? Ideas regarding some sort of mechanical sensor, which a priori should exist, have been proposed for decades. However, no responsible molecule has been identified conclusively for initiating mechanical signal in the heart. Among the divergent classes of molecules suggested as serving this role are proteins that couple the extraceullar matrix to the cytoskeleton (e.g., integrin-binding proteins, focal adhesion kinase). A muscle LIM protein (MLP)/telethonin (T-cap) complex in the Z-band of the sarcomere may be important in cardiomyocyte stretch sensing (Knoll et al., 2002). One recent study suggests that cell stretch causes a calcium-permeable, growth factor-regulated channel of the transient receptor potential family to translocate to the sarcolemma; overexpression of this channel causes cardiomyopathy in mice (Iwata et al., 2003). For some cells, stretch-activated nuclear calcium channels mediate the transcriptional response to changes in cell shape (Itano et al., 2003). It is not known if this is true for the heart. While the most-proximal stem in mechanotransduction is still the least defined, functionally important downstream signals generated because of load on the heart are many and varied.

As in applying Koch's postulates of causality to other biological problems, dissecting the cascades for cardiac hypertrophy entails finding mediators that ultimately fulfill the following experimental critieria: 1) they are induced or more active after load; 2) they are sufficient to promote one or more components of hypertrophy when supplied exogenously or expressed as a gain-of-function mutation; and 3) they can be shown to be necessary for one or more components 
of hypertrophy when their repression or function is blocked. Perhaps the best-posed proximal mediators for cardiac hypertrophy are heterotrimeric $G$ proteins (Adams and Brown, 2001). G protein-coupled receptors of relevance to cardiac hypertrophy include those for the cardiac agonists angiotensin II, endothelin-1 (ET-1), and $\alpha_{1}$-adrenergic ligands, each of which has trophic effects on cardiac myocytes apart from peripheral actions such as vasoconstriction. The $\mathrm{G}$ proteins implicated in cardiac hypertrophy include $G_{\alpha q}, G_{11}, G_{\alpha s}$, and $G_{\alpha i}$, with the case being especially strong for $G_{\alpha q}$ and $G_{11}$, acting redundantly. Other components of this signal transduction pathway include but are not limited to the mitogen-activated protein kinase (MAPK) family, protein kinase $\mathrm{C}(\mathrm{PKC})$, phosphatidylinositol 3-kinase (PI3-K), Akt, calmodulin-dependent protein kinases, and the calmodulin-dependent phosphatase calcineurin (Molkentin et al., 1998; Bueno et al., 2000; Zhang et al., 2000; Chen et al., 2001; Molkentin and Dorn, 2001; Crackower et al., 2002; Minamino et al., 2002; Shioi et al., 2002; Olson and Schneider, 2003). Of these, we will return to $G_{\alpha q}$ and calcineurin subsequently.

A central event for signal transduction in hypertrophy is the modification of ubiquitous and cardiac-enriched transcription factors. The former group includes cyclic AMP (cAMP)-responsive element binding protein/activating transcription factor (CREB/ATF), nuclear factor of activated T cells (NFAT), class II histone deacetylases, and histone acetylases (p300, CREB-binding protein), whereas the latter includes serum response factor (SRF), myocyte enhancer factor-2 (MEF2), homeodomain protein $\mathrm{Nkx} 2.5$, and zinc finger protein GATA4, with proteins of both classes serving as coactivators. Transcriptional adaptors that promote the assembly of multifactor complexes are themselves the target of signaling cascades that control key functional properties, such as histone acetylase activity or nuclear localization. Among other targets, these alterations turn on the set of genes known as immediate-early transcription factors (e.g., Fos, Myc, Jun, Egr-1). Certain of the newly synthesized, repressed, and modified proteins influence upstream components of the hypertrophic pathway, activating their activators, activating parallel modules, or providing a negative-feedback loop. Relationships among the pathways for hypertrophy are labyrinthine but no more so than, say, for the cell cycle in proliferating cells. Like "transformation" in cancer biology, which is more-instructively viewed in terms of its discrete elements (e.g., loss of replicative senescence, escape from apoptosis, tumor angiogenesis, metastasis), the hypertrophic phenotype is an aggregate of modular responses - including plasticity of cardiac gene expression (activation of a largely fetal-like gene program), production of growth factors and cytokines, apoptosis, and fibrosis - of which myocyte enlargement is the pathognomic one.

The physical enlargement of cardiomyocytes occurs through a global increase in RNA and protein content per cell. Knowledge concerning the mechanisms for hypertrophic growth is surprisingly scant, compared to the wealth of 
new insights concerning transcriptional plasticity (Olson and Schneider, 2003). In this review, we consider recent discoveries that implicate the phosphorylation of RNA polymerase II (RNAPII) in cardiac hypertrophy at the sites that are crucial for transcription elongation (Sano et al., 2002; Sano and Schneider, 2003). What kinases are responsible? How do hypertrophic cascades couple to the kinases? What is the evidence that changes in the RNAPII-directed protein kinase circuit are causative with respect to growth? Is such growth adaptive, phenotypically neutral, or adverse?

\section{The RNAPII Phosphorylation-Dephosphorylation Cycle}

RNA transcription - which genes are expressed and at what levels - is integral not only to the definition of cell identity during lineage decisions for embryogenesis but also to the cell's adaptation to the environment in diverse pathophysiological states. Hence, transcription is the executor of both "nature" and "nurture." mRNA synthesis directly couples the DNA genetic code to the cell- and organ-level phenotypes that are manifested as the consequence of protein expression: genome, transcriptome, proteome, and phenome. Yet, RNA transcription encompasses three phases - initiation, elongation, and termination - of which just the first has been studied widely (Orphanides and Reinberg, 2002). Transcription initiation begins with the formation of a preinitiation complex that brings together many general transcription factors that bind DNA and one another, including the general transcription factors TFIIA, TFIIB, TFIIC, TFIID, TFIIE, TFIIF, and the subunits of RNAPII. The carboxy-terminal domain (CTD) of the largest subunit of RNAPII contains an evolutionally conserved, 52-copy repeat of a 7-amino acid motif (YSPTSPS).

RNAPII is recruited to promoters in its hypophosphorylated form (RNAPIIa) and subsequently phosphorylated at Ser2 and Ser5 of the heptapeptide repeat, in the transition from initiation to elongation (Komarnitsky et al., 2000; Lin et al., 2002; Orphanides and Reinberg, 2002; Pokholok et al., 2002; Shim et al., 2002; Shilatifard et al., 2003). Importantly, the state of phosphorylation of the CTD is critical to transcription initiation, elongation, and mRNA processing, rather than merely denoting this change of state. Two kinases responsible for phosphorylation of the CTD are cyclin-dependent kinase 7 (Cdk7) (Roy et al., 1994) and Cdk9 (Zhu et al., 1997). Cdk7 phosphorylates Ser5 of the heptapeptide repeat between initiation and promoter clearance, whereas $\mathrm{Cdk} 9$ phosphorylates the CTD at Ser2, allowing RNAPII to overcome proximal promoter pausing and migrate into the open reading frame (Orphanides and Reinberg, 2002). The names of these two kinases allude to cyclins as their principal binding partners: cyclin $\mathrm{H}$ for Cdk7 (Makela et al., 1994) and cyclin T or K for Cdk9 (Peng et al., 1998a,b). The cyclin H/Cdk7 complex has a third component with the morethan-usually memorable name, ménage-a-trois (MAT1) (Devault et al., 1995; 
Tassan et al., 1995a). In carrying out its role as a CTD kinase, this trimeric complex is part of the larger general transcription factor TFIIH (Serizawa et al., 1995; Shiekhattar et al., 1995). Cyclin H/Cdk7 also functions as a Cdk-activating kinase (CAK), regulating different phases of the cell cycle by activating other Cdks (Fisher and Morgan, 1994; Harper and Elledge, 1998). The presence of MAT1 in the complex is thought to shift the substrate preference towards the RNAPII CTD (Rossignol et al., 1997; Yankulov and Bentley, 1997).

The cyclin T/Cdk9 heterodimer is known as positive transcription elongation factor-b (P-TEFb) (Marshall and Price, 1992,1995; Conaway and Conaway, 1999; Price, 2000). The cyclin T family is made up of three isoforms - cyclin $\mathrm{T} 1$, cyclin $\mathrm{T} 2 \mathrm{a}$, and cyclin $\mathrm{T} 2 \mathrm{~b}$ - which are known to be functionally distinct in some settings. More distantly related, cyclin $\mathrm{K}$ also activates Cdk9. Among the known specificities, the best-studied is Cdk9's recruitment to the human immunodeficiency virus (HIV) genome exclusively by cyclin T1, via the HIV Tat protein and a 59-base transactivation-responsive region (TAR) in the $5^{\prime}$ untranslated region (UTR) of nascent HIV transcripts (Wimmer et al., 1999). Several transcription factors are reported to bind cyclin T2 preferentially (Simone et al., 2002a,b). Negative regulators of transcript elongation include negative elongation factor (NELF) and DRB sensitivity-inducing factor (DSIF) (Wada et al., 2000; Yamaguchi et al., 2002). To inhibit positive transcription elongation, DSIF binds to RNAPII directly and NELF binds to nascent RNA transcripts and RNAPII/DSIF (Yamaguchi et al., 2002). The ability of Cdk9 to promote elongation occurs in part by impairing the association of RNAPII with these key inhibitors. Thus, CTD phosphorylation by $\mathrm{Cdk} 9$ enables RNAPII to migrate into the open reading frame and differing elongation factors are bound to the polymerase, depending on position.

Dephosphorylation of the CTD takes place after transcription termination, through the action of a specific TFIIF-associated CTD phosphatase, FCP1 (Cho et al., 1999; Kobor et al., 1999; Kobor and Greenblatt, 2002; Lin et al., 2002; Kamada et al., 2003). FCP1 may preferentially dephosphorylate Ser2 of the CTD (Hausmann and Shuman, 2002) (cf. Lin et al., 2002), whereas a new family of small CTD phosphatases preferentially dephosphorylates the CTD at Ser5 (Yeo et al., 2003). By catalyzing this dephosphorylation after transcription termination, FCP1 prepares RNAPII for another round of transcription. FCP1 likely has an additional role in transcript elongation beyond its function as a CTD phosphatase (Kobor and Greenblatt, 2002; Mandal et al., 2002). Both functions are regulated through its phosphorylation by protein kinases that are yet to be identified (Friedl et al., 2003).

The RNAPII CTD is also the substrate for a third Cdk complex, cyclin $\mathrm{C} / \mathrm{Cdk} 8$. In this case, however, the kinase acts as a negative regulator of transcription, by phosphorylating the CTD before RNAPII is recruited to promoters (Tassan et al., 1995b; Hengartner et al., 1998; Akoulitchev et al., 2000). 
Hyperphosphorylated RNAPII cannot be recruited to promoters; thus, Cdk8 prevents transcription from commencing. Cdk8 also phosphorylates cyclin $\mathrm{H}$, repressing the CTD kinase activity of TFIIH and disrupting its ability to activate transcription (Akoulitchev et al., 2000).

This phosphorylation-dephosphorylation cycle - in its relation to the cardiac growth signals we studied - is illustrated, in abbreviated form, in Figure 1 (upper panel).

\section{Cdk7 and Cdk9 Are Targets of the Signaling Cascades for Biomechanical Stress}

Bridging the two ideas described earlier - increased RNA content per cell and the established mechanism of transcription elongation - might Cdk7 and Cdk9 be important in cardiac hypertrophy? For this to be true, Cdk7, Cdk9, or both would first need to be expressed and active in the heart. Indeed, both kinases are expressed and active in embryonic myocardium, with function decreasing dramatically from the embryo stage to the adult, as measured by immune complex kinase assays and the phosphorylation of endogenous RNAPII (Sano et al., 2002) (Figure 1a, left). This downregulation was readily explained by the downregulation of both Cdks and the two corresponding cyclins as the heart matures. The net result was a fall in the fraction of phosphorylated RNAPII in myocardium, from $30 \%$ in embryos to just $4 \%$ in normal adults.

Conversely, both Cdk7 and Cdk9 were activated during chronic cardiac hypertrophy in vivo, provoked by means of biomechanical stress (partial aortic constriction) and by two of its genetically best-proven downstream mediators, $\mathrm{G}_{\alpha \mathrm{q}}$ (Adams et al., 1998; Wettschureck et al., 2001) and calcineurin (Molkentin et al., 1998; Rothermel et al., 2001). In contrast, acute mechanical stress caused activation only of Cdk9, not Cdk7 (Figure 1a, right). The same was true for isolated neonatal rat cardiomyocytes challenged with ET-1 (Sano et al., 2002). Hence, the principal difference observed was between long-term and short-term growth signals, not between hypertrophy of the intact heart and its surrogate in cultured cells.

The preference for Cdk9 activation as a ubiquitous or at least highly generalizable response to hypertrophic cues prompted the hypothesis that Cdk9 might be the more important of these two CTD kinases in cardiac hypertrophy. Furthermore, Cdk9 has the important technical and conceptual advantages inherent to being an immediate-early response and, hence, is perhaps more likely to be direct. Using catalytically inactive dominant-negative (dn) forms of both kinases, it was demonstrated that dn Cdk9 was sufficient to block ET-1-induced hypertrophy in cultured cardiomyocytes, whereas dn Cdk7 was not (Sano et al., 2002) (Figure 1b). Under these conditions, at least, Cdk9 was essential for myocyte growth. As other critieria to support this interpretation, similar results 
were obtained using 5,6-dichloro-1-D-ribofuranosylbenzimidazole, a pharmacological inhibitor of transcript elongation that is active preferentially against Cdk9. Furthermore, the phosphorylation of RNAPII triggered by ET-1 occurred at Ser2 of the heptapeptide repeat, the site preferred by Cdk9 (Sano et al., 2002).

\section{Trophic Signals Dissociate an Endogenous Inhibitor from Cdk9}

A quandary remained: how was $\operatorname{Cdk} 9$ becoming activated in these four pathobiological settings - ET-1, $\mathrm{G}_{\alpha \mathrm{q}}$, calcineurin, and biomechanical stress and was a unitary mechanism possibly shared across this series of interrelating signals? A more-specific mystery was that many common and expected mechanisms were easily excluded. Unlike the easy and intuitively satisfying explanation for downregulation of CTD kinase activity with age (the observed downregulation of all four proteins, the two kinases and their two cyclins), no analogous change was occurring as an early response to trophic signals to account for the rapid reinduction of Cdk9 activity: neither levels of Cdk9, levels of the $\mathrm{T}$ cyclins, nuclear localization, nor physical assembly of cyclin T/Cdk9 heterodimers increased (Sano et al., 2002).

In 2001, two groups independently identified an astounding endogenous inhibitor of the cyclin T/Cdk9 complex, namely "7SK," a small nuclear RNA (snRNA) of no prior established function (Nguyen et al., 2001; Yang et al., 2001). Based on this breakthrough, the presence of the inhibitor in physical association with cardiac P-TEFb was ascertained directly, using immune complex reverse transcription-polymerase chain reaction (RT-PCR) and sequencing the recovered cDNA (Sano et al., 1999). Binding was confirmed independently using biotinylated RNA complementary to 7SK snRNA for affinity purification, then Western blotting for the co-recovered proteins. In all the hypertrophic models we studied, acute and chronic alike, the activation of Cdk9 occurred through dissociation of this 7SK transcript (Sano et al., 2002) (Figure 1c).

The next question asked was, if signals for cardiac hypertrophy can activate Cdk9, can activating Cdk9 suffice to cause hypertrophy? As pivotal evidence supporting a causal role of the endogenous inhibitor, antisense 7SK was sufficient to increase Cdk9 activity and RNA production (Sano et al., 2002) (Figure 1c). Thus, pharmacological, physiological, and genetic instigators of hypertrophy each removed an inhibitor from $\mathrm{Cdk} 9$, whereas removing the inhibitor, by suppressing its expression, was enough to activate Cdk9 and elicit spontaneous growth. Whereas this antisense study ablating 7SK snRNA answered the question conclusively for cultured cells, a corresponding answer for mouse myocardium was sought by forcibly expressing cyclin $\mathrm{T} 1$ at the level normal for embryonic or neonatal myocardium. To accomplish this, transgenic mice were engineered using the cardiomyocyte-specific $\alpha$-myosin heavy chain (MHC) promoter to overexpress cyclin $\mathrm{T} 1$ in the heart. $\mathrm{Cdk} 9$ activation and concentric 


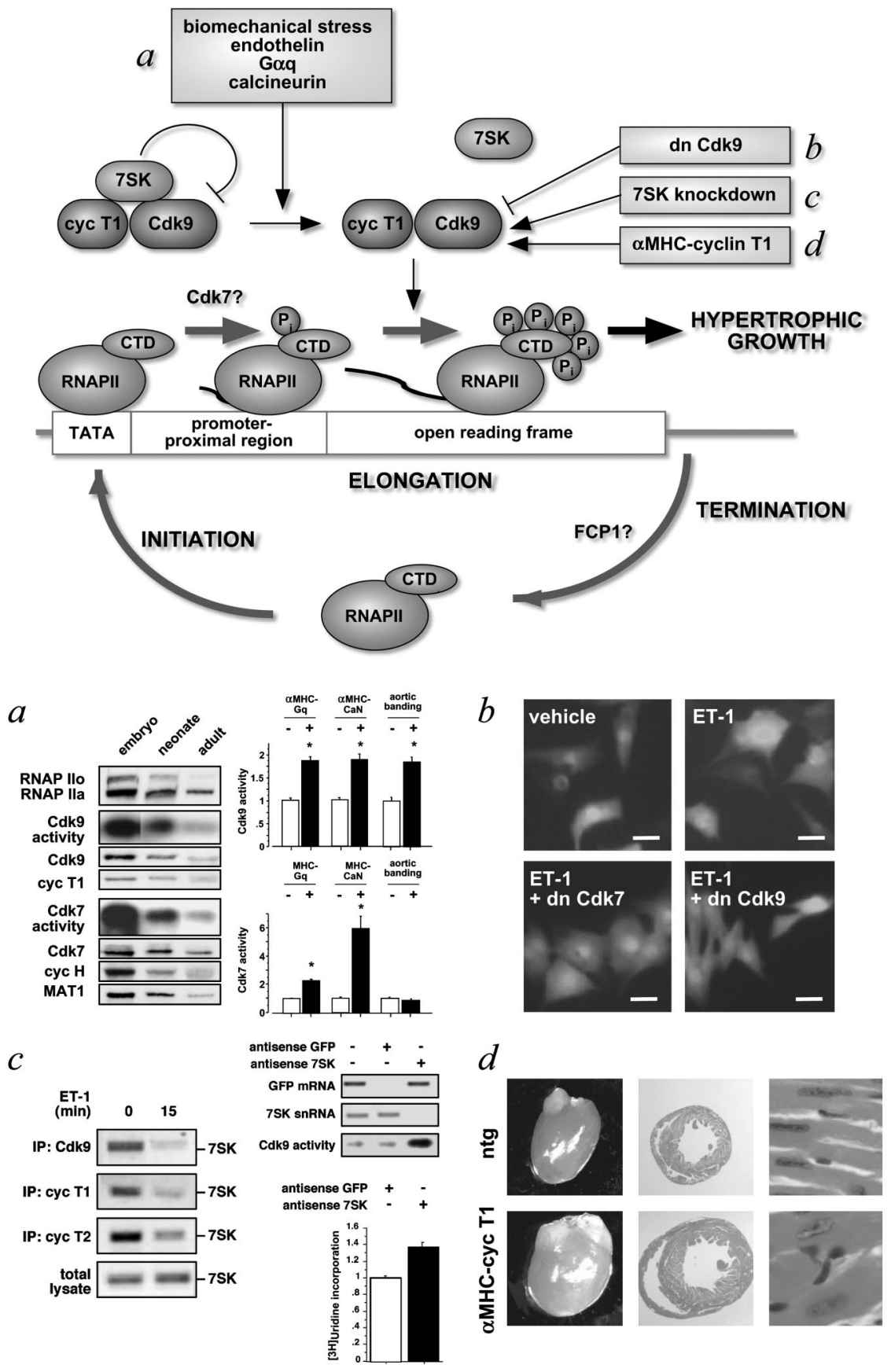


cardiac hypertrophy resulted, in a dose-dependent fashion, evidenced by an increase in the heart-weight-to-body-weight ratio and in myocyte size (Sano et al., 2002) (Figure 1d).

\section{Cdk9 as a Therapeutic Target}

The published findings summarized earlier point to $\mathrm{Cdk} 9$ as a potentially druggable target for intervention in the future. The logic for this is simple and builds plausibly on the knowledge that increased cardiac mass, in populationbased studies of heart disease, is a potent and independent risk factor for cardiac demise (reviewed in Sano and Schneider, 2002). If cardiac hypertrophy is ultimately harmful to the organism, beyond some given duration or threshold for growth, perhaps blocking the activity of $\operatorname{Cdk} 9$, at least partially, might be beneficial in the treatment of heart disease, by reducing cardiomyocyte growth. Yet, this extrapolation rests on several untested assumptions.

First, if Cdk9 is to be a therapeutic target in humans and not just in mice, then it must be demonstrably germane to human heart disease. In preliminary studies of human heart failure, we recently confirmed the predicted increase in Cdk9 and Cdk7 activity (M. Sano and M.D. Schneider, unpublished results).

Second, even if this is the case, does increasing Cdk9 activity confer increased risk of developing heart failure? Cyclin T1 transgenic mice, our model of Cdk9 activation, appear grossly normal, apart from heart size, under unstressed conditions. Increasingly, however, there is recognition that manipulations of the genome can be incompletely informative or even misleading, if the "phenome" is studied merely as a basal state. This was true, for example, in our prior studies of a proximal MAPK kinase kinase, MEKK1. With little or no findings from the germline deletion by itself, a critical role for MEKK1 was unmasked when tested in the context of a Gq gain-of-function: deleting MEKK1 prevented $\mathrm{G}_{\alpha q}$-induced growth (Minamino et al., 2002). Like $\mathrm{G}_{\alpha \mathrm{q}}$ at the dose studied, cyclin $\mathrm{T} 1$ was well tolerated as a gain-of-function mutation, expressed at the level normal in earlier stages of life, each transgene resulting separately in

FIG. 1 (facing page). Activation and function of the positive transcription elongation factor-b (P-TEFb) (cyclin T/Cdk9) in cardiac muscle hypertrophy. (Upper panel) Schematic representation of the RNA polymerase II (RNAPII) phosphorylation-dephosphorylation cycle and its modulation by physiological, pharmacological, and genetic triggers of hypertrophy. Upstream signals (a) and direct manipulations of $\mathrm{Cdk} 9$ activity (b-d) correspond to data illustrated in the lower panels. [Reproduced and modified from Sano M, Abdellatif M, Oh H, Xie M, Bagella L, Giordano A, Michael LH, DeMayo FJ, Schneider MD 2002 Activation and function of cyclin T-Cdk9 (positive transcription elongation factor-b) in cardiac muscle-cell hypertrophy. Nature Med 8:1310-1317, with permission of the Nature Publishing Group.] 
mild concentric hypertrophy without cell death, fibrosis, or overt dysfunction. However, crossing cyclin $\mathrm{T} 1$ with $\mathrm{G}_{\alpha \mathrm{q}}$ transgenic mice - creating the doubletransgenic model - increased Cdk9 activity more so than either alone, increased the heart-weight-to-body-weight ratio more than either of the single transgenics, and induced apoptosis, with the functional sequelae of heart failure and early demise (M. Sano and M.D. Schneider, unpublished data). Completely blocking the increase of Cdk9 function in cardiomyocytes with $\mathrm{dnCdk} 9$ prevented Gqinduced growth, yet was tolerated poorly under stress. The same exacerbation and mortality were true, using mechanical load as the hypertrophic signal, in concert with dnCdk9 or cyclin T1. This suggests that Cdk9 is an essential protein at some intermediate level of activity and that graded, titratable inhibition, whether genetic or drug based, would more likely be of benefit than complete disruption of this signaling module.

\section{Unanswered Questions and Future Prospects}

In summary, we have shown that $\mathrm{Cdk} 7$ and $\mathrm{Cdk} 9$ both become activated by chronic mechanical load or genetic triggers of hypertrophy, using the $\mathrm{G}$ protein $\mathrm{G}_{\alpha \mathrm{q}}$ and the calcium-dependent phosphatase calcineurin. Each of these in transgenic mice reproduces and may be essential for the hypertrophic phenotype (Sano et al., 2002). In acute load or cell-culture models of cardiac hypertrophy, only Cdk9 activity increased. Across this gamut of hypertrophic triggers (hemodynamic, genetic, and pharmacological), a unifying property was activation of Cdk9 not by increased assembly with its functional partner cyclin $\mathrm{T}$ but, rather, through dissociation of a remarkable endogenous inhibitor, the noncoding 7SK snRNA. Cdk9 function was sufficient to compel hypertrophic growth in culture (shown by an antisense knockdown of 7SK snRNA), obligatory for hypertrophy in culture (shown by dnCdk9), and sufficient for hypertrophy in mouse myocardium (shown by forced expression of its activator cyclin T1). Findings that implicate $\mathrm{Cdk} 9$ as a potential therapeutic target in cardiac disease also include the abnormally increased activity of this kinase in human heart failure and the catastrophic interaction between cyclin $\mathrm{T} 1$ and other hypertrophic cues in transgenic mouse models.

$\mathrm{P}-\mathrm{TEFb}$ - the cyclin T/Cdk9 heterodimer - lies at an intriguing interface between the forefront of fundamental studies into general transcription factors, on the one hand, and disease-driven studies of pathobiological growth, on the other. Tantalizing insights are emerging but many questions surrounding its structure, activity, and function remain to be answered.

Consider, first, its endogenous inhibitor, the 7SK snRNA. Recent findings implicate a novel protein, ménage a quatre (MAQ1), as recruited to the $\mathrm{N}$ terminal homology region of cyclin $\mathrm{T}$ via this noncoding transcript, a relationship that resembles (and competes with) the binding of cyclin T1 by the HIV Tat 
protein and HIV TAR RNA. Thus, it has been proposed that lentivirus has subverted the regulation of P-TEFb by the MAQ1-7SK protein-RNA complex (Michels et al., 2003). However, the participation of MAQ1 in growth signaling in vivo and its specific function even in cell culture are still mysteries. Futhermore, even though the 7SK-MAQ1 complex was found to inhibit P-TEFb function, it is unknown how signals release this complex from $\mathrm{P}-\mathrm{TEFb}$ and which component of the complex is their primary target.

Several cyclins besides T1 partner with Cdk9, including cyclins T2a and $\mathrm{T} 2 \mathrm{~b}$, the alternatively spliced products of a separate gene. Like cyclin T1, the T2 cyclins are found in the cardiac P-TEFb/7SK RNA complex but, unlike cyclin T1, both are upregulated highly in the adult heart, compared to myocardium of the embryo or neonate (Sano et al., 2002). Aside from Tat binding just to cyclin $\mathrm{T} 1$, functional distinctions among these isoforms are largely conjectures.

Taking a step back from the partnering cyclins, Cdk9 has been shown to associate with other proteins in the cell, such as the molecular chaperones heat shock protein 70 and chaperone complex Hsp90/cyclin-dependent complex 37 (O'Keeffe et al., 2000). Whereas activation of Cdk9 in acute hypertrophic models was traced, thus far, only to the dissociation of 7SK RNA, the chronic hypertrophic models were found to cause not only decreased binding of the inhibitor but also increased expression of the chaperone proteins and increased assembly of cyclin T/Cdk9 (M. Sano and M.D. Schneider, unpublished data). Is this pathway needed for normal activation of Cdk9? Conversely, are Cdk9 activation and its resulting impact on transcription essential targets of these chaperones?

To date, we have learned more of Cdk9 than of Cdk7 in the coupling of hypertrophic signals to RNAPII phosphorylation. However, it should not be overlooked that all chronic hypertrophic signals (long-term load, $\mathrm{G}_{\alpha \mathrm{q}}$, and calcineurin) also activated this second of the CTD kinases. Experimentallly, the barriers to studying Cdk7 activation in cardiac hypertrophy are formidable, as no in vitro model has been identified in which its activation is perturbed and activation of Cdk7 in vivo has, thus far, always been concomitant with activation of Cdk9 (Sano et al., 2002). What, then, is the role, if any, of Cdk7? If consequential, how is its activity regulated by the growth signals that also impinge on Cdk9? Conversely, for RNAPII to be competent for recruitment into the preinitiation complex, it must be in the dephosphorylated form. Although critical to the cycling of RNAPII, nothing is presently known about the CTD phosphatases in cardiac hypertrophy.

Although the results discussed here are interpreted in the broadest possible biochemical context - namely, the function of CTD phosphorylation in transcription elongation generically - it can be envisioned that some genes might be regulated more than others by this mode of transcriptional control. As yet, nothing is known of specific genes' susceptibility to regulation by hypertrophic 
signals at this step. Such an understanding of CTD kinases in cardiac hypertrophy is likely to require both flavors of scientific "chips" - genome-wide microarray comparisons of gene expression and, more mechanistically, chromatin immunoprecipitation. The latter would be indispensable to pinpoint promoter escape and identify the protein-protein associations that occur with the elongating form of RNAPII provoked by cardiac growth signals.

\section{REFERENCES}

Adams JW, Brown JH 2001 G-proteins in growth and apoptosis: lessons from the heart. Oncogene 20:1626-1634

Adams JW, Sakata Y, Davis MG, Sah VP, Wang YB, Liggett SB, Chien KR, Brown JH, Dorn GW 1998 Enhanced G alpha q signaling: a common pathway mediates cardiac hypertrophy and apoptotic heart failure. Proc Natl Acad Sci USA 95:10140-10145

Akazawa H, Komuro I 2003 Roles of cardiac transcription factors in cardiac hypertrophy. Circ Res 92:1079-1088

Akoulitchev S, Chuikov S, Reinberg D 2000 TFIIH is negatively regulated by cdk8-containing mediator complexes. Nature 407:102-106

Bueno OF, De Windt LJ, Tymitz KM, Witt SA, Kimball TR, Klevitsky R, Hewett TE, Jones SP, Lefer DJ, Peng CF, Kitsis RN, Molkentin JD 2000 The MEK1-ERK1/2 signaling pathway promotes compensated cardiac hypertrophy in transgenic mice. EMBO J 19:6341-6350

Chen L, Hahn H, Wu G, Chen CH, Liron T, Schechtman D, Cavallaro G, Banci L, Guo Y, Bolli R, Dorn GW II, Mochly-Rosen D 2001 Opposing cardioprotective actions and parallel hypertrophic effects of delta PKC and epsilon PKC. Proc Natl Acad Sci USA 98:1111411119

Cho H, Kim TK, Mancebo H, Lane WS, Flores O, Reinberg D 1999 A protein phosphatase functions to recycle RNA polymerase II. Genes Dev 13:1540-1552

Conaway JW, Conaway RC 1999 Transcription elongation and human disease. Annu Rev Biochem 68:301-319

Crackower M, Oudit G, Kozieradzki I, Sarao R, Sun H, Sasaki T, Hirsch E, Suzuki A, Shioi T, Irie-Sasaki J, Sah R, Cheng H, Rybin V, Lembo G, Fratta L, Oliveira-dos-Santos A, Benovic J, Kahn C, Izumo S, Steinberg S, Wymann M, Backx P, Penninger J 2002 Regulation of myocardial contractility and cell size by distinct PI3K-PTEN signaling pathways. Cell 110:737

Devault A, Martinez AM, Fesquet D, Labbe JC, Morin N, Tassan JP, Nigg EA, Cavadore JC, Doree M 1995 MAT1 ("menage a trois") a new RING finger protein subunit stabilizing cyclin H-cdk7 complexes in starfish and Xenopus CAK. EMBO J 14:5027-5036

Fisher RP, Morgan DO 1994 A novel cyclin associates with MO15/CDK7 to form the CDKactivating kinase. Cell 78:713-724

Frey N, Olson EN 2003 Cardiac hypertrophy: the good, the bad, and the ugly. Annu Rev Physiol 65:45-79

Friedl EM, Lane WS, Erdjument-Bromage H, Tempst P, Reinberg D 2003 The C-terminal domain phosphatase and transcription elongation activities of FCP1 are regulated by phosphorylation. Proc Natl Acad Sci USA 100:2328-2333

Harper JW, Elledge SJ 1998 The role of Cdk7 in CAK function, a retro-retrospective. Genes Dev 12:285-289

Hausmann S, Shuman S 2002 Characterization of the CTD phosphatase Fcp1 from fission yeast. Preferential dephosphorylation of serine 2 versus serine 5. J Biol Chem 277:21213-21220 
Hengartner CJ, Myer VE, Liao SM, Wilson CJ, Koh SS, Young RA 1998 Temporal regulation of RNA polymerase II by Srb10 and Kin28 cyclin-dependent kinases. Mol Cell 2:43-53

Hunter JJ, Chien KR 1999 Signaling pathways for cardiac hypertrophy and failure. N Engl J Med 341:1276-1283

Itano N, Okamoto S, Zhang D, Lipton SA, Ruoslahti E 2003 Cell spreading controls endoplasmic and nuclear calcium: a physical gene regulation pathway from the cell surface to the nucleus. Proc Natl Acad Sci USA 100:5181-5186

Iwata Y, Katanosaka Y, Arai Y, Komamura K, Miyatake K, Shigekawa M 2003 A novel mechanism of myocyte degeneration involving the $\mathrm{Ca} 2+$-permeable growth factor-regulated channel. J Cell Biol 161:957-967

Kamada K, Roeder RG, Burley SK 2003 Molecular mechanism of recruitment of TFIIFassociating RNA polymerase C-terminal domain phosphatase (FCP1) by transcription factor IIF. Proc Natl Acad Sci USA 100:2296-2299

Knoll R, Hoshijima M, Hoffman HM, Person V, Lorenzen-Schmidt I, Bang ML, Hayashi T, Shiga N, Yasukawa H, Schaper W, McKenna W, Yokoyama M, Schork NJ, Omens JH, McCulloch AD, Kimura A, Gregorio CC, Poller W, Schaper J, Schultheiss HP, Chien KR 2002 The cardiac mechanical stretch sensor machinery involves a $\mathrm{Z}$ disc complex that is defective in a subset of human dilated cardiomyopathy. Cell 111:943-955

Kobor MS, Greenblatt J 2002 Regulation of transcription elongation by phosphorylation. Biochim Biophys Acta 1577:261-275

Kobor MS, Archambault J, Lester W, Holstege FC, Gileadi O, Jansma DB, Jennings EG, Kouyoumdjian F, Davidson AR, Young RA, Greenblatt J 1999 An unusual eukaryotic protein phosphatase required for transcription by RNA polymerase II and CTD dephosphorylation in S. cerevisiae. Mol Cell 4:55-62

Komarnitsky P, Cho EJ, Buratowski S 2000 Different phosphorylated forms of RNA polymerase II and associated mRNA processing factors during transcription. Genes Dev 14:2452-2460

Lin PS, Marshall NF, Dahmus ME 2002 CTD phosphatase: role in RNA polymerase II cycling and the regulation of transcript elongation. Prog Nucleic Acid Res Mol Biol 72:333-365

MacLellan WR, Schneider MD 2000 Genetic dissection of cardiac growth control pathways. Annu Rev Physiol 62:289-320

Makela TP, Tassan JP, Nigg EA, Frutiger S, Hughes GJ, Weinberg RA 1994 A cyclin associated with the CDK-activating kinase MO15. Nature 371:254-257

Mandal SS, Cho H, Kim S, Cabane K, Reinberg D 2002 FCP1, a phosphatase specific for the heptapeptide repeat of the largest subunit of RNA polymerase II, stimulates transcription elongation. Mol Cell Biol 22:7543-7552

Marshall NF, Price DH 1992 Control of formation of two distinct classes of RNA polymerase II elongation complexes. Mol Cell Biol 12:2078-2090

Marshall NF, Price DH 1995 Purification of P-TEFb, a transcription factor required for the transition into productive elongation. J Biol Chem 270:12335-12338

Michels AA, Nguyen VT, Fraldi A, Labas V, Edwards M, Bonnet F, Lania L, Bensaude O 2003 MAQ1 and 7SK RNA interact with CDK9/cyclin T complexes in a transcription-dependent manner. Mol Cell Biol 23:4859-4869

Minamino T, Yujiri T, Terada N, Taffet GE, Michael LH, Johnson GL, Schneider MD 2002 MEKK1 is essential for cardiac hypertrophy and dysfunction induced by Gq. Proc Natl Acad Sci USA 99:3866-3871

Molkentin JD, Dorn GW II 2001 Cytoplasmic signaling pathways that regulate cardiac hypertrophy. Annu Rev Physiol 63:391-426

Molkentin JD, Lu JR, Antos CL, Markham B, Richardson J, Robbins J, Grant SR, Olson EN 1998 A calcineurin-dependent transcriptional pathway for cardiac hypertrophy. Cell 93:215228 
Nguyen VT, Kiss T, Michels AA, Bensaude O 2001 7SK small nuclear RNA binds to and inhibits the activity of CDK9/cyclin T complexes. Nature 414:322-325

O'Keeffe B, Fong Y, Chen D, Zhou S, Zhou Q 2000 Requirement for a kinase-specific chaperone pathway in the production of a Cdk9/cyclin $\mathrm{T} 1$ heterodimer responsible for $\mathrm{P}-\mathrm{TEFb}$-mediated tat stimulation of HIV-1 transcription. J Biol Chem 275:279-287

Olson EN, Schneider MD 2003 Sizing up the heart: development redux in disease. Genes Dev 17(16): 1937-1956

Orphanides G, Reinberg D 2002 A unified theory of gene expression. Cell 108:439-451

Pasumarthi KB, Field LJ 2002 Cardiomyocyte cell cycle regulation. Circ Res 90:1044-1054

Peng J, Marshall NF, Price DH 1998a Identification of a cyclin subunit required for the function of Drosophila P-TEFb. J Biol Chem 273:13855-13860

Peng J, Zhu Y, Milton JT, Price DH 1998b Identification of multiple cyclin subunits of human P-TEFb. Genes Dev 12:755-762

Pokholok DK, Hannett NM, Young RA 2002 Exchange of RNA polymerase II initiation and elongation factors during gene expression in vivo. Mol Cell 9:799-809

Price DH 2000 P-TEFb, a cyclin-dependent kinase controlling elongation by RNA polymerase II. Mol Cell Biol 20:2629-2634

Rossignol M, Kolb Cheynel I, Egly JM 1997 Substrate specificity of the cdk-activating kinase (CAK) is altered upon association with TFIIH. EMBO J 16:1628-1637

Rothermel BA, McKinsey TA, Vega RB, Nicol RL, Mammen P, Yang J, Antos CL, Shelton JM, Bassel-Duby R, Olson EN, Williams RS 2001 Myocyte-enriched calcineurin-interacting protein, MCIP1, inhibits cardiac hypertrophy in vivo. Proc Natl Acad Sci USA 98:3328-3333

Roy R, Adamczewski JP, Seroz T, Vermeulen W, Tassan JP, Schaeffer L, Nigg EA, Hoeijmakers JH, Egly JM 1994 The MO15 cell cycle kinase is associated with the TFIIH transcriptionDNA repair factor. Cell 79:1093-101

Sadoshima J, Izumo S 1997 The cellular and molecular response of cardiac myocytes to mechanical stress. Annu Rev Physiol 59:551-571

Sano M, Schneider MD 2002 Still stressed out but doing fine: normalization of wall stress is superfluous to maintaining cardiac function in chronic pressure overload. Circulation 105: $8-10$

Sano M, Schneider MD 2003 Cyclins that don't cycle: cyclin t/cyclin-dependent kinase-9 determines cardiac muscle cell size. Cell Cycle 2:99-104

Sano Y, Harada J, Tashiro S, Gotoh-Mandeville R, Maekawa T, Ishii S 1999 ATF-2 Is a common nuclear target of Smad and TAK1 pathways in transforming growth factor-beta signaling. J Biol Chem 274:8949-8957

Sano M, Abdellatif M, Oh H, Xie M, Bagella L, Giordano A, Michael LH, DeMayo FJ, Schneider MD 2002 Activation and function of cyclin T-Cdk9 (positive transcription elongation factor-b) in cardiac muscle-cell hypertrophy. Nature Med 8:1310-1317

Serizawa H, Makela TP, Conaway JW, Conaway RC, Weinberg RA, Young RA 1995 Association of Cdk-activating kinase subunits with transcription factor TFIIH. Nature 374:280-282

Shiekhattar R, Mermelstein F, Fisher RP, Drapkin R, Dynlacht B, Wessling HC, Morgan DO, Reinberg D 1995 Cdk-activating kinase complex is a component of human transcription factor TFIIH. Nature 374:283-287

Shilatifard A, Conaway RC, Conaway JW 2003 The RNA polymerase II elongation complex. Annu Rev Biochem 72:693-715

Shim EY, Walker AK, Shi Y, Blackwell TK 2002 CDK-9/cyclin T (P-TEFb) is required in two post-initiation pathways for transcription in the $C$. elegans embryo. Genes Dev 16:2135-2146

Shioi T, McMullen JR, Kang PM, Douglas PS, Obata T, Franke TF, Cantley LC, Izumo S 2002 Akt/protein kinase B promotes organ growth in transgenic mice. Mol Cell Biol 22:2799-2809 
Simone C, Bagella L, Bellan C, Giordano A 2002a Physical interaction between pRb and cdk9/cyclinT2 complex. Oncogene 21:4158-4165

Simone C, Stiegler P, Bagella L, Pucci B, Bellan C, De Falco G, De Luca A, Guanti G, Puri PL, Giordano A 2002b Activation of MyoD-dependent transcription by cdk9/cyclin T2. Oncogene 21:4137-4148

Tassan JP, Jaquenoud M, Fry AM, Frutiger S, Hughes GJ, Nigg EA 1995a In vitro assembly of a functional human CDK7-cyclin $\mathrm{H}$ complex requires MAT1, a novel $36 \mathrm{kDa}$ RING finger protein. EMBO J 14:5608-5617

Tassan JP, Jaquenoud M, Leopold P, Schultz SJ, Nigg EA 1995b Identification of human cyclin-dependent kinase 8, a putative protein kinase partner for cyclin C. Proc Natl Acad Sci USA 92:8871-8875

Wada T, Orphanides G, Hasegawa J, Kim DK, Shima D, Yamaguchi Y, Fukuda A, Hisatake K, Oh S, Reinberg D, Handa H 2000 FACT relieves DSIF/NELF-mediated inhibition of transcriptional elongation and reveals functional differences between $\mathrm{P}-\mathrm{TEFb}$ and TFIIH. Mol Cell 5:1067-1072

Wettschureck N, Rutten H, Zywietz A, Gehring D, Wilkie TM, Chen J, Chien KR, Offermanns S 2001 Absence of pressure overload induced myocardial hypertrophy after conditional inactivation of Galphaq/Galpha11 in cardiomyocytes. Nature Med 7:1236-1240

Wimmer J, Fujinaga K, Taube R, Cujec TP, Zhu Y, Peng J, Price DH, Peterlin BM 1999 Interactions between Tat and TAR and human immunodeficiency virus replication are facilitated by human cyclin T1 but not cyclins T2a or T2b. Virology 255:182-189

Yamaguchi Y, Inukai N, Narita T, Wada T, Handa H 2002 Evidence that negative elongation factor represses transcription elongation through binding to a DRB sensitivity-inducing factor/RNA polymerase II complex and RNA. Mol Cell Biol 22:2918-2927

Yang Z, Zhu Q, Luo K, Zhou Q 2001 The 7SK small nuclear RNA inhibits the CDK9/cyclin T1 kinase to control transcription. Nature 414:317-322

Yankulov KY, Bentley DL 1997 Regulation of CDK7 substrate specificity by MAT1 and TFIIH. EMBO J 16:1638-1646

Yeo M, Lin PS, Dahmus ME, Gill GN 2003 A novel RNA polymerase II C-terminal domain phosphatase that preferentially dephosphorylates serine 5. J Biol Chem 278:26078-26085

Yussman MG, Toyokawa T, Odley A, Lynch RA, Wu G, Colbert MC, Aronow BJ, Lorenz JN, Dorn GW 2002 Mitochondrial death protein Nix is induced in cardiac hypertrophy and triggers apoptotic cardiomyopathy. Nature Med 8:725-730

Zhang D, Gaussin V, Taffet GE, Belaguli NS, Yamada M, Schwartz RJ, Michael LH, Overbeek PA, Schneider MD 2000 TAK1 is activated in the myocardium after pressure overload and is sufficient to provoke heart failure in transgenic mice. Nature Med 6:556-563

Zhu Y, Pe'ery T, Peng J, Ramanathan Y, Marshall N, Marshall T, Amendt B, Mathews MB, Price DH 1997 Transcription elongation factor P-TEFb is required for HIV-1 tat transactivation in vitro. Genes Dev 11:2622-2632 